\title{
Buttock pain after sacrospinous hysteropexy: reply to Wallner
}

\author{
V. Dietz • M. Huisman • J. M. de Jong • P. M. Heintz • \\ C. H. van der Vaart
}

Received: 24 April 2008 / Accepted: 25 April 2008 / Published online: 21 June 2008

(C) The Author(s) 2008

\section{Dear Editor,}

We greatly appreciate the comment by Dr. Wallner [1] on the new insight into the positioning of the pudendal and levator ani nerves in relation to the complaint of buttock pain after sacrospinous hysteropexy [2]. The anatomical work that has currently been done in this important surgical region is of value not only to all surgeons performing sacrospinous ligament fixation, but also to those working with needle placement for synthetic implants in the posterior compartment.
Open Access This article is distributed under the terms of the Creative Commons Attribution Noncommercial License which permits any noncommercial use, distribution, and reproduction in any medium, provided the original author(s) and source are credited.

\section{References}

1. Wallner C (2008) Buttock pain after sacrospinous hysteropexy. Int Urogynecol J doi:10.1007/s00192-008-0646-3

2. Functional outcome after sacrospinous hysteropexy for uterine descensus. Int Urogynecol J 19:747-752 doi:10.1007/s00192-007-0520-8

V. Dietz $(\varangle) \cdot$ M. Huisman $\cdot$ J. M. de Jong $\cdot$ P. M. Heintz $\cdot$

C. H. van der Vaart

Department of Perinatology and Gynecology,

University Medical Center Utrecht,

Room F05.126, Heidelberglaan 100, P.O. Box 85500,

3508 GA Utrecht, The Netherlands

e-mail: viviane.dietz@sapio.nl 